\title{
Effect of Bi Addition on Tensile Properties of Sn-Ag-Cu Solder at Low Temperature
}

\author{
Yukihiko Hirai $^{1,2, *}$, Kouki Oomori ${ }^{2}$, Hayato Morofushi ${ }^{2}$ and Ikuo Shohji ${ }^{1}$ \\ ${ }^{1}$ Division of Mechanical Science and Technology, Faculty of Science and Technology, Gunma University, Kiryu 376-8515, Japan \\ ${ }^{2}$ Keihin Corporation, Shioya-gun, Tochigi 329-1233, Japan
}

In order to examine the effect of the Bi addition on tensile properties of $\mathrm{Sn}-\mathrm{Ag}-\mathrm{Cu}$ solder at low temperatures, stress-strain diagrams were acquired by tensile tests at $233 \mathrm{~K}$ using miniature size specimens. Stress drops were observed in the stress-strain diagram of $\mathrm{Sn}-\mathrm{Ag}-\mathrm{Cu}-\mathrm{Bi}$ solder before it lead to a break. Similar phenomenon did not observed in the $\mathrm{Sn}-\mathrm{Ag}-\mathrm{Cu}$ solder. The stress drops was exceptionally sharp in the $\mathrm{Sn}-\mathrm{Ag}-\mathrm{Cu}$ solder with added 3 mass $\% \mathrm{Bi}$, compared to the solder with added 1 or 2 mass $\% \mathrm{Bi}$. The mode of the stress drop is depended on twin deformation. On the contrary, similar stress drop phenomenon was not observed in any stress-strain diagrams at $298 \mathrm{~K}$. From the results of grain map analysis, it was found that many twin deformations occur in the specimen in which exceptional sharp stress drops appear in the stress-strain diagram. [doi:10.2320/matertrans.MH201807]

(Received January 28, 2019; Accepted April 1, 2019; Published May 25, 2019)

Keywords: lead-free solder, tin-silver-copper-bismuth, tensile test, stress-strain diagram, low temperature

\section{Introduction}

Automotive electronic control units are used under severe environmental conditions around the world, and thus it is required that operation of the units should be guaranteed over a range from low temperature to high temperature such as $233-423 \mathrm{~K}^{1)}$ Also, lead-free solder has come to be used in accordance with the 2006 Restriction of Hazardous Substances (RoHS) Directive, and $\mathrm{Sn}-3.0$ mass\% Ag-0.5 mass\% $\%$ u (SAC305) solder recommended by Japan Electronics and Information Technology Industries Association $(\text { JEITA })^{2,3)}$ has been used for automotive products widely in Japan. At present, $\mathrm{Sn}-\mathrm{Ag}-\mathrm{Cu}$ lead-free solder in which $\mathrm{Bi}$ is solid-solved has been proposed due to requirements for higher reliability. ${ }^{4)}$ However, material properties of this alloy type solder at low temperatures have not been almost reported. ${ }^{5,6)}$

Generally, material properties of solder materials have been evaluated with the relative large size specimen specified in JIS Z 3198-2 in Japan. ${ }^{7,8)}$ The specimen is the dumbbell type and the diameter is $8 \mathrm{~mm}$. Figures 1 and 2 show microstructures observation results for the JIS Z 3198-2 specimen and the real ball grid array (BGA) solder joint, respectively. In the figures, grain map of Sn by electron backscatter diffraction (EBSD) analysis images are also shown. The microstructure of the large size specimen is different from that of the BGA joint. Also, the BGA joint is a single crystal although the large size specimen is a polycrystal. Such difference in microstructures leads to the difference in material properties of both specimens.

Kariya has proposed the miniature size specimen to investigate the mechanical properties of the solder material used in the real solder joint. ${ }^{9)}$ Figure 3 shows the microstructure of the dumbbell type miniature size specimen with $0.5 \mathrm{~mm}$ diameter fabricated with SAC305 solder. From a comparison of Figs. 2 and 3, it was confirmed that the miniature size specimen has similar microstructure to the BGA joint with SAC305 solder.

*Graduate Student, Gunma University. Corresponding author, E-mail: yukihiko-hirai@keihin-corp.co.jp (a)

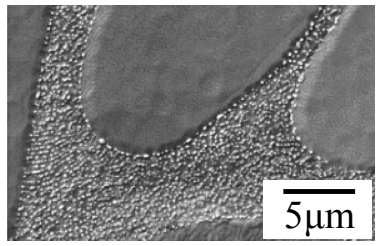

(b)

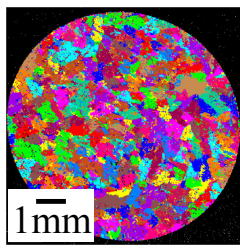

Fig. 1 Microstructure of JIS Z3198-2 specimen with SAC305 solder. (a) Back-scattered electron image, (b) Grain map by EBSD analysis.

(a)

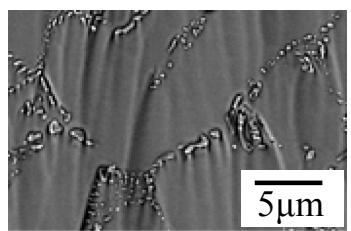

(b)

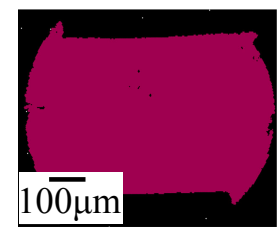

Fig. 2 Microstructure of BGA joint with SAC305 solder. (a) Backscattered electron image, (b) Grain map by EBSD analysis.

(a)

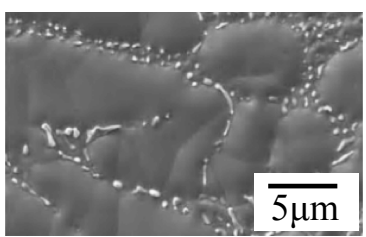

(b)

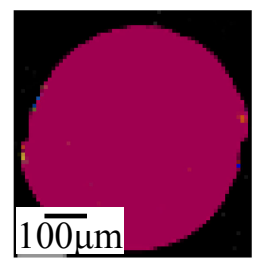

Fig. 3 Microstructure of dumbbell type miniature size specimen with SAC305 solder (diameter: $0.5 \mathrm{~mm}$ ). (a) Back-scattered electron image, (b) Grain map by EBSD analysis.

Therefore, in this study, the tensile properties of SAC305 solder with added $\mathrm{Bi}$ were investigated at low temperature using miniature size specimens.

\section{Experimental Procedure}

\subsection{Fabrication method of miniature size specimen}

A commercially available SAC305 solder wire with $1.0 \mathrm{~mm}$ diameter was prepared. Table 1 indicates the chemical compositions of solder investigated in this study. Three $\mathrm{Sn}-\mathrm{Ag}-\mathrm{Cu}-\mathrm{Bi}$ solder, which are $\mathrm{SAC} 305-1 \mathrm{Bi},-2 \mathrm{Bi}$ and $-3 \mathrm{Bi}$, were fabricated. Figure 4 shows the shape and 
Table 1 Chemical compositions of solder investigated (mass $\%$ ).

\begin{tabular}{ccccc}
\hline Solder type & $\mathrm{Ag}$ & $\mathrm{Cu}$ & $\mathrm{Bi}$ & $\mathrm{Sn}$ \\
\hline SAC305 & 3.0 & 0.5 & - & Bal. \\
\hline SAC305-1Bi & 3.0 & 0.5 & 1.0 & Bal. \\
\hline SAC305-2Bi & 3.0 & 0.5 & 2.0 & Bal. \\
\hline SAC305-3Bi & 3.0 & 0.5 & 3.0 & Bal. \\
\hline
\end{tabular}

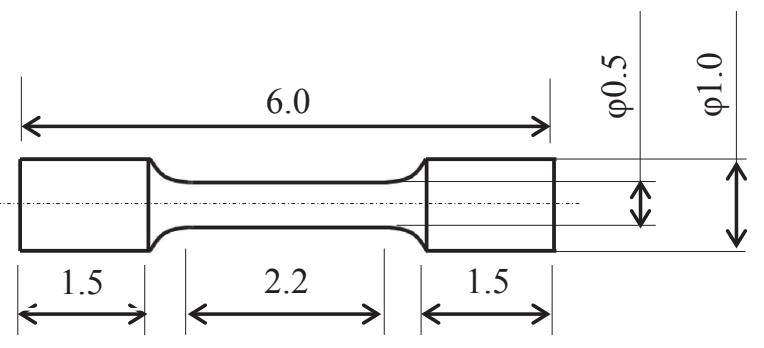

Fig. 4 Shape and dimensions of miniature size specimen.

(a)

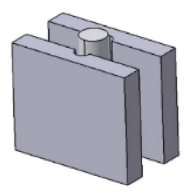

(c)

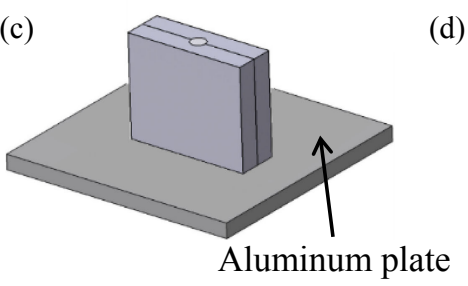

Fig. 5 Fabrication process of miniature size specimen. (a) Setting wire into mold, (b) Heating, (c) Cooling, (d) Extraction of specimen.

dimensions of the miniature size specimen fabricated in this study. The preparation method of specimens for each solder was as follows. Firstly, the necessary amounts of SAC305, $\mathrm{Ag}, \mathrm{Cu}$ and $\mathrm{Bi}$ (Ag, $\mathrm{Cu}$ and $\mathrm{Bi}$ with purities of $99.9 \%$ or more) were weighed using an electronic balance to fabricate the alloy shown in Table 1. Secondly, the weighed mixture were heated in a solder bath set at $723 \mathrm{~K}$ for approximately 10 minutes to melt it, and then molten solder was cast into a cylindrical mold with the size of $\varphi 10 \mathrm{~mm} \times 20 \mathrm{~mm}$. The cast product was drawn to produce a solder wire of $\varphi 1.2 \mathrm{~mm}$. Next, the solder wire was set into a mold as shown in Fig. 5(a). The mold with the wire was heated to $573 \mathrm{~K}$ on a digital hot plate as shown in Fig. 5(b). After confirming that the solder was completely melted, the mold was cooled on an aluminum plate to solidify the solder as shown in Fig. 5(c). The cooling rate at this process was approximately $1.5 \mathrm{~K} / \mathrm{sec}$. This fabrication method of miniature size specimen was based on the reports ${ }^{10-12)}$ of Kariya et al.
Also, initial microstructural observations and element mapping of these specimens were carried out by the following methods. Firstly, initial specimens were encased in room temperature curing type epoxy resin. Secondly, the specimens were cut parallel to the longitudinal direction and polished by SiC abrasive paper \#500, \#800, \#1200, \#2400 and \#4000. The specimens were buffed by alumina abrasive of particle size $0.5 \mu \mathrm{m}$, and OP-S $\left(\mathrm{SiO}_{2}\right.$ of particle size $0.04 \mu \mathrm{m})$. After these processing, microstructure was observed by scanning electron microscopy (SEM) and qualitative analysis of matrix and precipitates in SAC-3Bi was carried out by electron probe micro analyzer (EPMA).

\subsection{Tensile test}

Tensile tests were conducted using a linear motor type material testing machine (TA Instrument 3220 Series III). The test temperature was $233 \mathrm{~K}$. In each test, the tensile specimen was set in the testing machine, and left at the test temperature for 30 minutes in order that the interior of the specimen reaches the test temperature. The tensile test was conducted at a strain rate of $4.5 \times 10^{-4} \mathrm{~s}^{-1}$ until fracture occurred. For comparison, the test was also conducted in the same manner at room temperature $(298 \mathrm{~K})$. The number of specimens was three in each condition because we referred the previous study ${ }^{13)}$ that reported that the crystallographic anisotropy of $\beta$-Sn greatly affects mechanical properties.

\subsection{Grain map analysis}

After each tensile test, the specimen was encased in room temperature curing type conductive epoxy resin. The specimen was cut parallel to the longitudinal direction and polished by $\mathrm{SiC}$ abrasive paper \#400, \#800, \#2000. Then specimen was processed by a cross section polisher. After these processing, grain map analysis by EBSD was conducted to investigate crystal grain morphology. The reason for choosing this analysis is that it is most suitable for processing data for identifying crystal grains induce twinning deformation. In this study, the crystal grain with a grain diverging from the adjacent crystal grain by $15^{\circ}$ or more, i.e. the high-angle grain boundary, was defined as the separate crystal.

\section{Results and Discussions}

\subsection{Microstructures of specimens}

Figure 6 shows the initial microstructures of SAC305-1Bi, SAC305-2Bi and SAC305-3Bi and Fig. 7 shows qualitative 
(a)

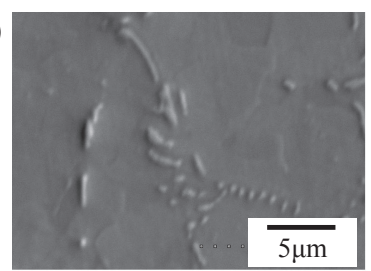

(b)
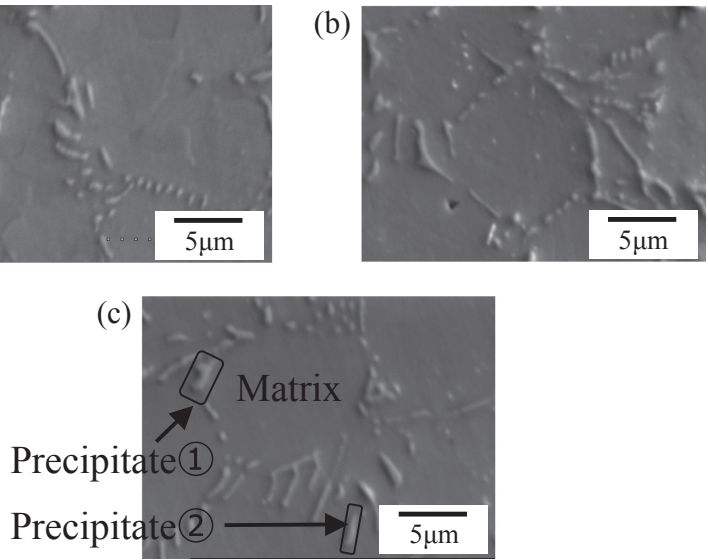

Fig. 6 Secondary electron images of tensile specimens. (a) SAC305-1Bi, (b) SAC305-2Bi, (c) SAC305-3Bi.

analysis results of matrix and precipitates in SAC305-3Bi. Regardless of the Bi content, similar microstructures with SAC305 were observed. From qualitative analysis results, $\mathrm{Ag}_{3} \mathrm{Sn}$ and $\mathrm{Cu}_{6} \mathrm{Sn}_{5}$ particles are precipitated in $\beta$-Sn phases and $\mathrm{Bi}$ is solid-solved in the matrix.

\subsection{Stress-strain diagrams}

Figure 8 shows three stress-strain diagrams of miniature size specimens at $233 \mathrm{~K}$. Stress drops were observed in SAC305-1Bi, -2Bi and -3Bi between the initial stage of the test and fracture. Although the similar phenomenon has been reported in the tensile test of single crystal of $\mathrm{Bi}$ at $298 \mathrm{~K},{ }^{14}$ ) there has been no report on $\mathrm{Sn}-\mathrm{Ag}-\mathrm{Cu}-\mathrm{Bi}$ solder. Compared to Figs. 8(b), (c) and (d), it was found that an exceptionally sharp stress drop occurs in SAC305-3Bi. Figure 8(e) shows the enlarged stress-strain diagram in the region where the sharp stress drop occurs in Fig. 8(d). From the figure, it was found that there are multiple aspects of sharp stress drops whereby an exceptional sharp stress drop occurs, the sharp stress drops occur several times or no sharp stress drop occurs. In addition, Fig. 9 shows the stress-strain diagrams obtained from tensile test at 298 K. At $298 \mathrm{~K}$, no sharp stress drops were observed in all specimens investigated.

Figure 10 shows tensile strength of investigated solder at $233 \mathrm{~K}$ and $298 \mathrm{~K}$. From this result, it was revealed that tensile strength increased by adding $\mathrm{Bi}$ in SAC305. Although the mean of tensile strength of SAC305-1Bi was almost equal to SAC305-2Bi, tensile strength of SAC305-3Bi was higher than that of SAC305-2Bi at $233 \mathrm{~K}$. Also, the mean of tensile strength at $298 \mathrm{~K}$ increased as quantity of addition of $\mathrm{Bi}$. In comparison with these results, tensile strength of investigated solder at $233 \mathrm{~K}$ was higher than those at $298 \mathrm{~K}$. In addition, the tensile strength of SAC305-3Bi was the highest at both temperatures. This reason tensile strength increased is solid solution strengthening by $\mathrm{Bi}$ because precipitate of $\mathrm{Bi}$ element was not observed in the microstructure.

\subsection{Grain map analysis}

Figure 11 shows grain map of fractured portions shown in Fig. 8(a) No. 1 and in Fig. 8(e) No. 2 and No. 3. A small quantity of fine crystal grains were observed in Figs. 11(a) and 11(b). On the other hand, a much greater quantity of fine crystal grains were observed in Fig. 11(c).

(a)

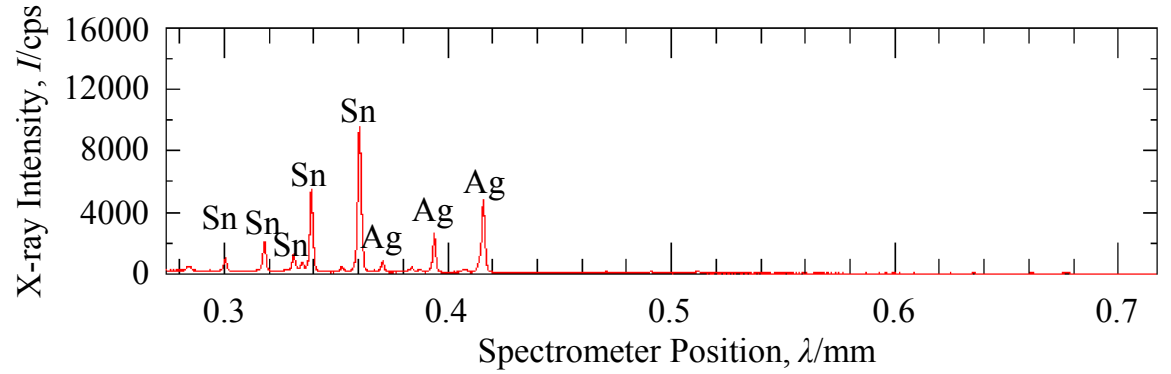

(b)

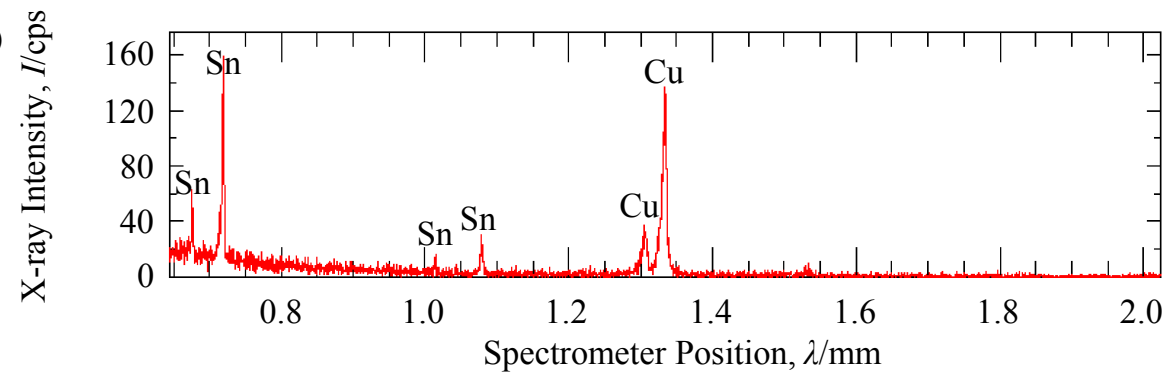

(c)

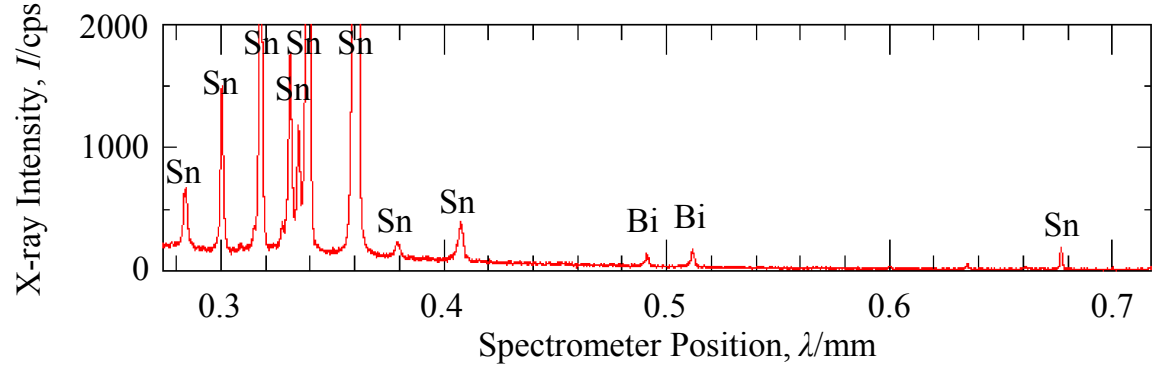

Fig. 7 Qualitative analysis results. (a) Precipitate(1), (b) Precipitate(2), (c) Matrix. 

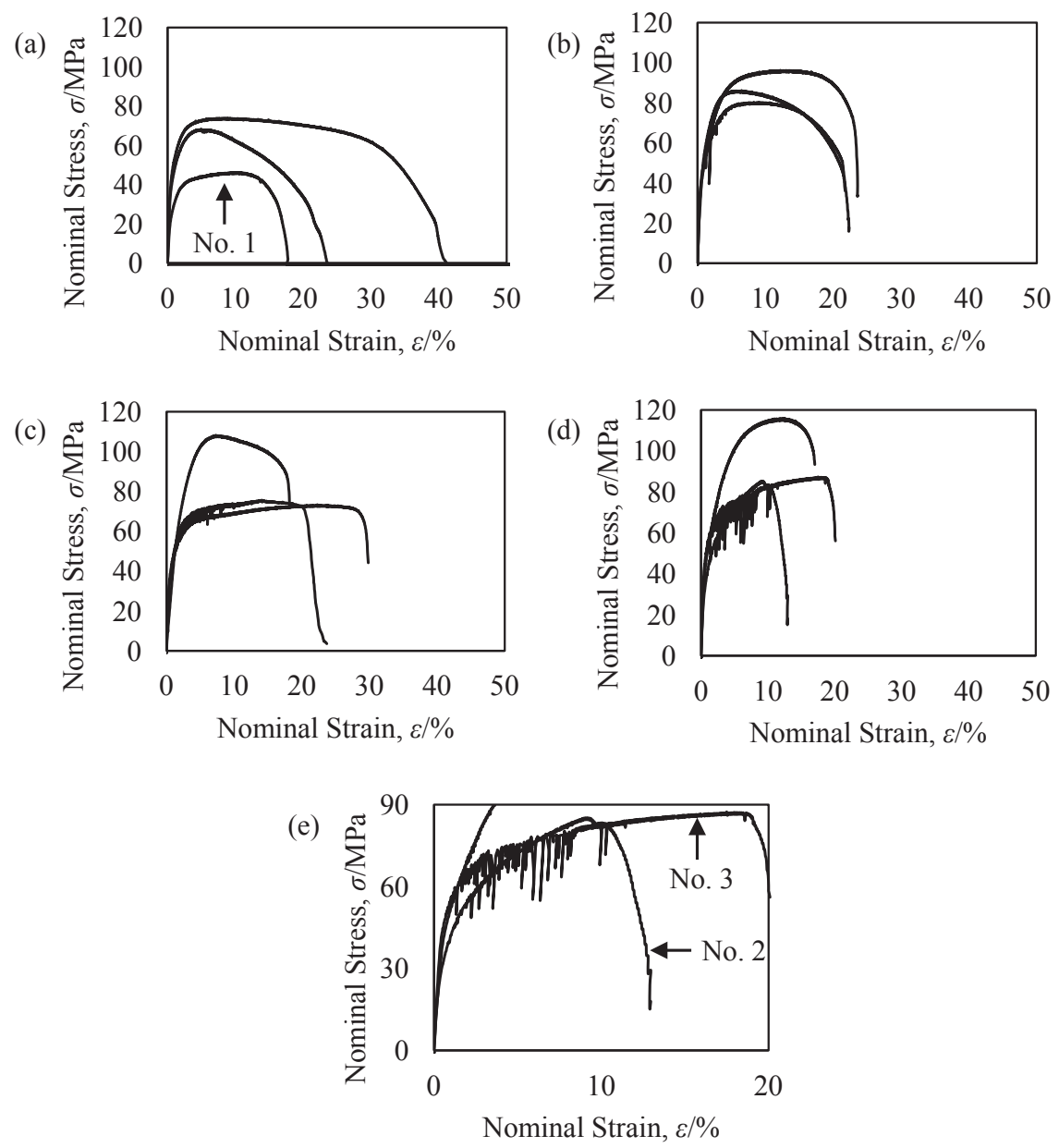

Fig. 8 Stress-strain diagrams at 233 K. (a) SAC305, (b) SAC305-1Bi, (c) SAC305-2Bi, (d) SAC305-3Bi, (e) Enlargement of Fig. 8(d).
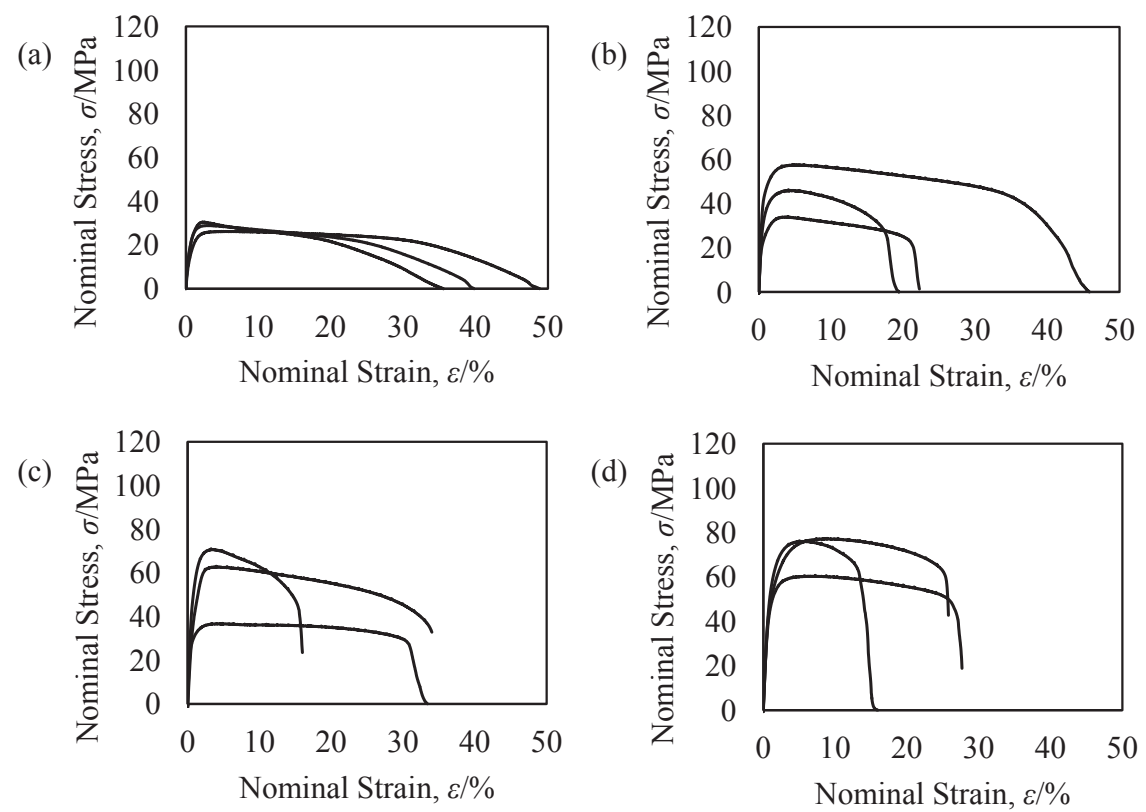

Fig. 9 Stress-strain diagrams at 298 K. (a) SAC305, (b) SAC305-1Bi, (c) SAC305-2Bi, (d) SAC305-3Bi.

Figure 12 shows the results of processed data to recognize the crystal grains as one crystal grain when there is an orientation difference between adjacent crystal grains with rotation axis [100] and a rotation angle of $60 \pm 2^{\circ}{ }^{15)}$ In such relationship, twin deformation easily occurs. Compared to Figs. 11 and 12, it was confirmed that approximately 20 and 30 fine crystal grains disappear in Figs. 12(a) and 12(b), respectively. On the other hand, it was confirmed that 

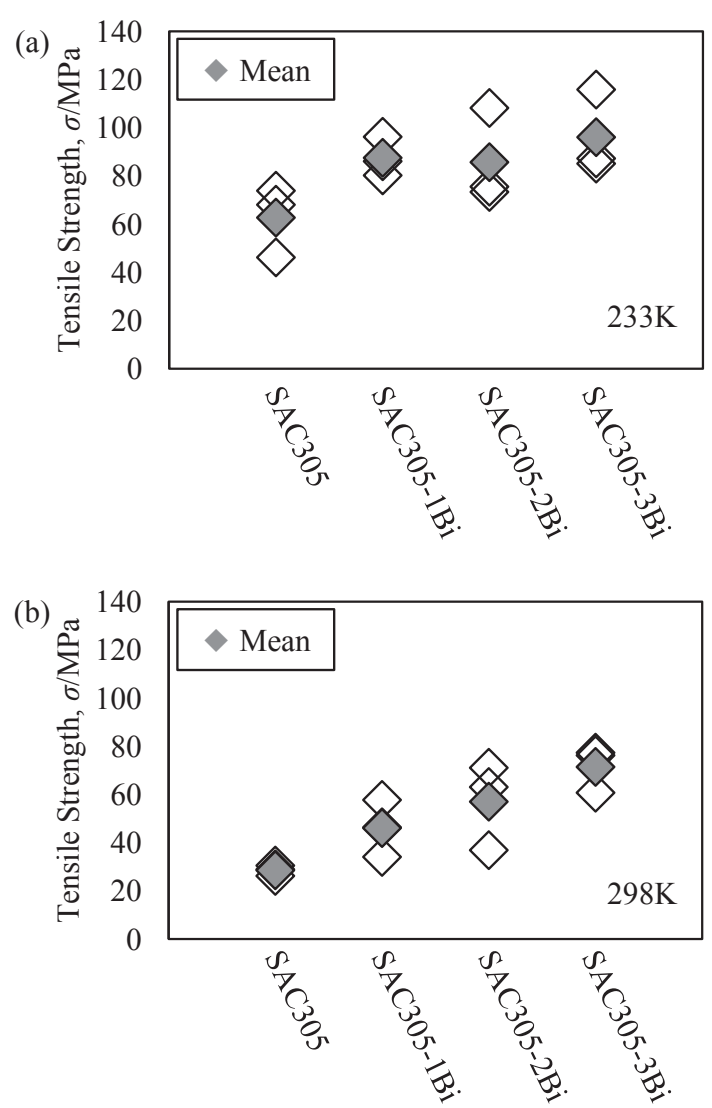

Fig. 10 Effect of $\mathrm{Bi}$ content and test temperature on tensile strength. (a) $233 \mathrm{~K}$, (b) $298 \mathrm{~K}$.

approximately 50 fine crystal grains disappear in Fig. 12(c). The grains surrounded in a dashed line in Fig. 11 disappear in Fig. 12. Sub grains near the fracture part in Fig. 12(b), (c) that are not disappeared by processing data were probably caused by dynamic recrystallization. ${ }^{16}$ ) Table 2 shows number of crystal grains disappeared by processing data. Therefore, the sharp stress drops appeared in Fig. 8 seem to
Table 2 Number of crystal grains disappeared by processing date.

\begin{tabular}{cc}
\hline Specimens & Number \\
\hline No. 1 & 20 \\
\hline No. 2 & 28 \\
\hline No. 3 & 47 \\
\hline
\end{tabular}

be caused due to the occurrence of many twin deformations. Therefore, the sharp stress drops appeared in Fig. 8 seem to be caused due to the occurrence of many twin deformations. Thus, it is suggested that this aspect of the stress drop is related to with the number of crystal grains which induce twin deformations, because many fine crystal grains due to twin deformations exist in the specimen in which an exceptionally sharp stress drop occurred (No. 3). In addition, a few fine crystal grains due to twin deformations exist in the specimen in which stress drops occurred several times (No. 2). Although crystal grains induced by twin deformations also existed in SAC305 (No. 1), the occurrence of stress drop was less evident because there was a lower quantity of them. Moreover, the exceptional sharp stress drop in the stress-strain diagram of SAC305-3Bi at $233 \mathrm{~K}$ seems to be caused by inhibition of movement of dislocations by the large amount of solid solution of $\mathrm{Bi}$ and inhibition of slip deformation. As a result, twin deformation occured easily.

\section{Conclusions}

The tensile properties of $\mathrm{Sn}-3.0$ mass $\% \mathrm{Ag}-0.5 \mathrm{mass} \% \mathrm{Cu}$ (SAC305) solder with added Bi were investigated at $233 \mathrm{~K}$ using miniature size specimens. The addition of $\mathrm{Bi}$ was changed from 1 to 3 mass $\%$ to investigate the effect of the $\mathrm{Bi}$ addition on the tensile properties. The obtained data were
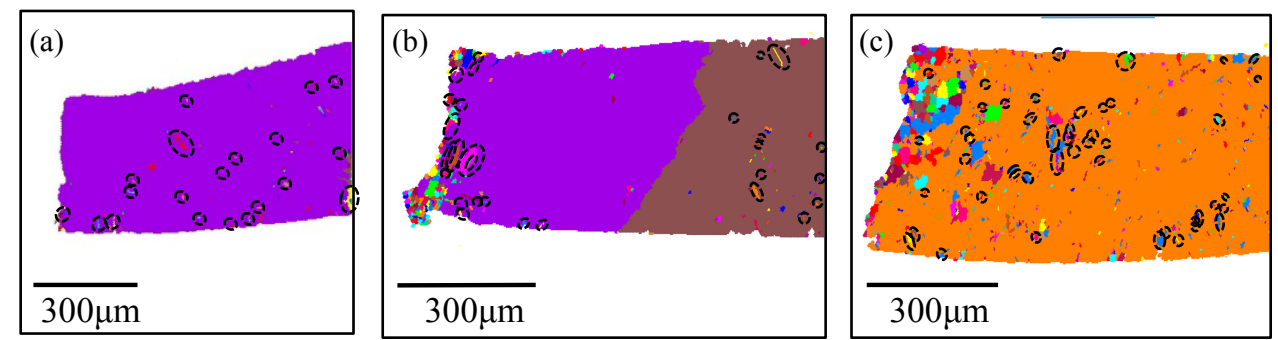

Fig. 11 Grain map by EBSD analysis. (a) No. 1 (in Fig. 8(a)), (b) No. 2 (in Fig. 8(e)), (c) No. 3 (in Fig. 8(e)).
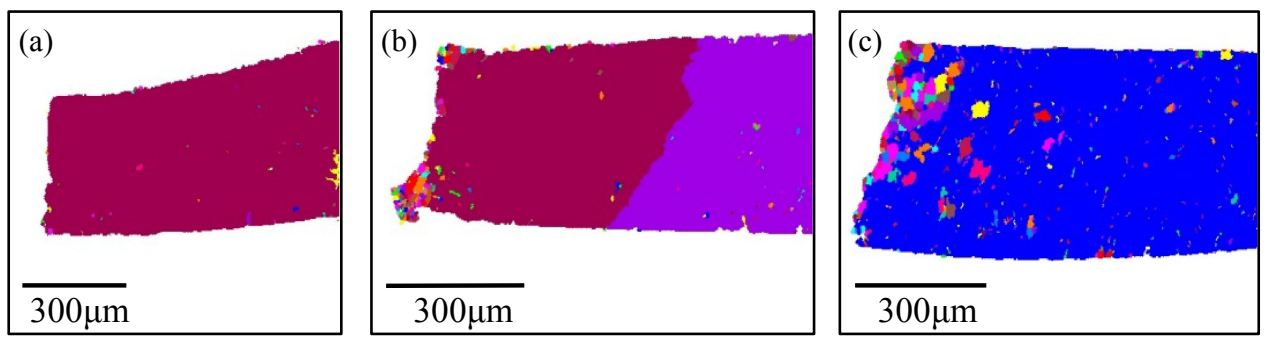

Fig. 12 Processed Grain map for maps shown in Fig. 11 (a) No. 1, (b) No. 2, (c) No. 3. 
compared to those at $298 \mathrm{~K}$. The obtained results of this study are summarized as follows.

(1) It was confirmed that a stress drop occurs in the stressstrain diagrams of SAC305-1Bi, SAC305-2Bi and SAC305-3Bi at $233 \mathrm{~K}$. Similar stress drop phenomenon was not seen at $298 \mathrm{~K}$.

(2) An exceptionally sharp stress drop occurs conspicuously in the stress-strain diagram of SAC305-3Bi at $233 \mathrm{~K}$. The aspect of the stress drop varies according to the specimen. In the specimen in which an exceptionally sharp stress drop was observed, a greater quantity of crystal grains with twin crystal crystal relation were seen.

(3) The tensile strength of SAC305 increased with increasing the addition of $\mathrm{Bi}$ at $233 \mathrm{~K}$ and $298 \mathrm{~K}$. Then tensile strength of SAC305-3Bi was the highest in the solder investigated in this study.

\section{REFERENCES}

1) R.W. Johnson, J.L. Evans, P. Jacobsen, J.R. Thompson and M. Christopher: IEEE Trans. Electron. Packag. Manuf. 27 (2004) 164-176.

2) Y. Takahashi and I. Shohji: Proc. 21st Symposium on Microjoining and Assembly Technology in Electronics, (The Japan Welding Society, 2015) pp. 165-168.
3) F. Takenouchi and A. Yamauchi: Proc. 21st Symposium on Microjoining and Assembly Technology in Electronics, (The Japan Welding Society, 2015) pp. 153-158.

4) S.A. Belyakov, J. Xian, G. Zeng, K. Sweatman, T. Nishimura, T. Akaiwa and C.M. Gourlay: J. Mater. Sci. doi:10.1007/s10854-0180302-8.

5) M.M.R. Chowdhury, S. Ahmed, A. Fahim, J.C. Suhling and P. Lall: Proc. 15th IEEE ITHERM Conference, (2016) pp. 1202-1208.

6) C. Kanchanomai, Y. Miyashita and Y. Mutoh: J. Electron. Mater. 31 (2002) 456-465.

7) A. Morozumi, H. Hokazono, Y. Nishimura, E. Mochizuki and Y. Takahashi: Trans. Japan Inst. Electron. Packag. 8 (2015) 8-17.

8) A. Fukuda, T. Yamada, N. Besshi and Y. Kashiba: J. Smart Proces. 3 (2014) 192-198.

9) Y. Kariya: J. Japan Inst. Electron. Packag. 9 (2006) 138-142.

10) Y. Kariya, T. Niimi, T. Suga and M. Otsuka: Mater. Trans. 46 (2005) 2309-2315.

11) Y. Kariya, T. Asai and T. Suga: Proc. SPIE 5852 (2005) 297-301.

12) Y. Kariya, T. Niimi, T. Suga and M. Otsuka: Proc. IPACK2005 73165, (2005) pp. 1827-1832.

13) Y. Kariya, S. Tajima and S. Yamada: Mater. Trans. 53 (2012) 20672071.

14) Y. Yanaka, Y. Kariya, H. Watanabe and H. Hokazono: J. Electron. Mater. 47 (2018) 594-603.

15) A.U. Telang and T.R. Bieler: J. Miner. Met. Mater. Soc. 57 (2005) 44 49.

16) K. Mitsui and I. Shohji: Proc. 21st Symposium on Microjoining and Assembly Technology in Electronics, (The Japan Welding Society, 2019) pp. 327-332. 